\title{
THERMAL ABSORPTIVITY MODEL OF KNITTED RIB FABRIC AND ITS EXPERIMENTAL VERIFICATION
}

\author{
Asif Elahi Mangat ${ }^{1}$, Lubos Hes ${ }^{1}$, Vladimir Bajzik', Adnan Mazari² \\ ${ }^{1}$ Technical University of Liberec KHT Department \\ ${ }^{2}$ Technical University of Liberec Clothing Department \\ correspondent author: asifmangat@gmail.com
}

\begin{abstract}
:
Thermal absorptivity is an indicator of warm and cool feeling of textile materials. An equation based on thermal absorptivity of polyester in solid form, porosity of a fabric, and relative contact area of human skin and fabric surface has been developed to characterize thermal absorptivity of fabric. For verification of suggested model, $15 \mathrm{knitted} \mathrm{rib}$ fabrics were produced using $100 \%$ polyester yarn and having different surface profile. ALAMBETA semiautomatic non-destructive instrument has been used for measuring the effective thermal absorptivity of knitted rib fabric. It was found that the suggested simple theoretical model exhibits significant agreement with the measured thermal absorptivity values of knitted rib fabric, which endorsed the approach applied.
\end{abstract}

\section{Keywords:}

Thermal absorptivity, rib knit fabric, contact area, porosity

\section{Thermal absorptivity an indicator of warm- cool feeling}

Heat flow between human skin and fabric is always due to the difference in temperature. If the temperature of skin is higher than that of the fabric, then heat from human body will transfer to the fabric and the person will observe a cool feel. This phenomenon is called warm-cool feeling [1-3]. Hes [4, 5] developed an equation to measure the warm-cool feeling of fabric and called it thermal absorptivity of fabric. Hes expressed that the thermal absorptivity depends on the thermal conductivity, specific heat capacity values, and density of the fabric and developed an instrument to measure the thermal absorptivity. This instrument is known as Alambeta; Hes confirmed the results of Alambeta by conducting a subjective evaluation. For subjective evaluation, Hes engaged 100 observers to assess warm-cool feeling of fabric and announced that there was a significant correlation between the thermal absorptivity measured using Alambeta and subjective evaluations. Thermal absorptivity is calculated using the following equation (1) [4].

$$
b=\sqrt{\lambda \rho C}
$$

where $b$ is the thermal absorptivity [W $\mathrm{s}^{0.5} \mathrm{~m}^{-2} \mathrm{~K}^{-1}$ ], $\lambda$ is the thermal conductivity [ $\mathrm{W} \mathrm{m}^{-1} \mathrm{~K}^{-1}$ ], $\rho$ represent the density [kg $\mathrm{m}^{-3}$, and $C$ is the specific heat capacity values $\left[\mathrm{J} \mathrm{kg}^{-1} \mathrm{~K}^{-1}\right.$. Thermal absorptivity values range from 20 to 900 . Higher values of thermal absorptivity indicate that there will be cool feeling on touching the fabric for a very short period of time. Dry fabrics made up of cotton gives the lowest value and highly wet fabric gives values above 900 . Moreover, it is also obvious that thermal absorptivity of different fibers and fabric will be different. For example, thermal conductivity of cotton is different from polyester. Also there is a drastic difference in specific heat capacity and density of different fibers and fabrics. Such differences will contribute in variation of thermal absorptivity of different fibers and fabrics [6, 7].

\section{Theory of Thermal absorptivity}

Hes and Dolezal $[6,8]$ presented a new approach, which was originally based on the idea of Yoneda and Kawabata. This approach was novel because it was not based on the environmental temperature. They called it thermal absorptivity and denoted it by $b$. The new concept of warm-cool feeling was based on other thermal and non-thermal properties of fabric. It was square root of the product of thermal conductivity, density, and specific heat of the fabric. This term was introduced by Hes in 1987 [9]. The value calculated can be used to express the thermal handle of textile. In this approach, two different bodies are considered ideal homogeneous semisolid having different temperature. Moreover, contact area is perpendicular to the normal line of heat flow. Time course is calculated using onedimensional partial differential equation

$$
\frac{\partial T}{\partial t}=a \frac{\partial^{2} T}{\partial x^{2}}
$$

where $a$ is the thermal diffusivity of the fabric $\left[\mathrm{m}^{2} \mathrm{~s}^{-1}\right]$, which is considered a pseudo-homogeneous solid. Thermal diffusivity is defined as the ratio of thermal conductivity $(\lambda)\left[\mathrm{W} \mathrm{m}^{-1} \mathrm{~K}^{-1}\right]$ and the volumetric heat capacity (c) $\left[\mathrm{J} \mathrm{kg}^{-1} \mathrm{~K}^{-1}\right]$ and density $(\rho)$ $\left[\mathrm{kg} \mathrm{m}^{-3}\right.$ ]

$$
a=\frac{\lambda}{c \rho}
$$


Hes and Dolezal [8] assumed that thermal absorptivity of body $1\left(b_{1}\right)$ is much higher than that of body $2\left(b_{2}\right)$. When these two bodies are put together, second body will take temperature $\left(t_{1}\right)$ of first body and second body in the longer distance will keep its original temperature $\left(t_{2}\right)$ intact. Gaussian error integral is a useful method to solve the issue using initial boundary conditions.

$$
\theta=\frac{t-t_{2}}{t_{1}-t_{2}}=\operatorname{erfc} \frac{x}{\sqrt{\pi \alpha_{2} \tau}}
$$

Using Fourier's law in its one-dimensional form, heat flow from one body to other during a time $\mathrm{T}$ can be determined.

$$
\begin{aligned}
& q(x=0)=-\lambda \frac{d \theta}{d x} \\
& q(x=0)=\frac{b}{\sqrt{\pi \tau}}\left(t_{1}-t_{2}\right)
\end{aligned}
$$

It is obvious from the final equation that coefficient of heat absorptivity $b$ enables an unambiguous calculation of heat flow between two bodies through contact area. In addition to that, there are much chances of accuracy because the bodies have finite dimension and the time is too short. It has been assumed that because of short time, two bodies are semisolid. Consider that the depth of penetration of heat is less than the thickness of the body, $h 1$, and contact time is

$$
\tau>\frac{h^{2}}{12,96 a}
$$

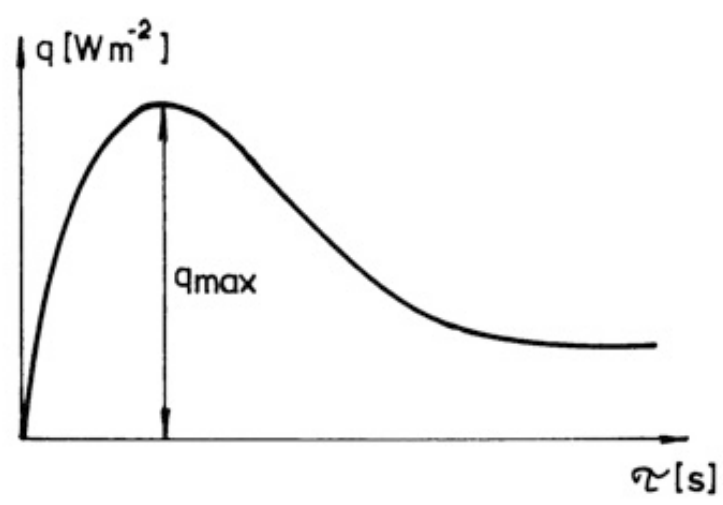

Figure 1. The process of heat flow in skin during thermal contact with a fabric [8]

In particular conditions, the basic differential equation will be solved using Laplace transform. In this equation, zero condition related the difference between the temperature of the fabric and that of the base and environment

$$
\theta(0, p)=t(x, 0)-t_{0}=0
$$

Following equation can be found doing transformation

$$
\frac{d^{2} \theta(x, p)}{d x^{2}}-\frac{p}{a} \theta(x, p)=0
$$

Using boundary conditions, the heat flow $q\left[\mathrm{~W} \mathrm{~m} \mathrm{~m}^{-2}\right]$ through fabric can be found as follows:

$$
q=\frac{b\left(t_{1}-t_{1}\right)}{\sqrt{\pi \tau}}
$$

where $t$ is the temperature, is the time of contact between human skin and textile material, and $b$ is the thermal absorptivity [W $\mathrm{s}^{0.5} \mathrm{~m}^{-2} \mathrm{~K}^{-1}$ ] and is calculated using the following equation. This was the final equation that was used by Hes [4] to measure the thermal absorptivity of any fabric.

$$
b=\sqrt{\lambda \rho C}
$$

where $\rho C$ is the thermal capacity of the material $\left[\mathrm{J} \mathrm{m}^{-3} \mathrm{~K}^{-1}\right]$ and $\lambda$ is the thermal conductivity [ $\mathrm{W} \mathrm{m}^{-1} \mathrm{~K}^{-1}$ ]. Thermal absorptivity values range from 20 to 600 . Higher values of thermal absorptivity indicate that there will be a cool feeling on touching the fabric for a very short period of time. Dry fabrics made up of cotton gives the lowest value and highly wet fabric gives values above 600 . Literature provides a number of studies conducted to find out the relationship between thermal absorptivity and various factors related to fabric. But there is no model available in the literature for the prediction of such important factor of fabric. This study is a noteworthy contribution in knowledge and provides a method for the prediction of thermal absorptivity of fabric.

Rengasamy, Das, and Patil have pointed out its significance in depth [10]. They explored that thermal absorptivity of fabric depends on the changes in smoothness/roughness of the surface of fabric. It is mainly due to the contact area required for the heat flow through conduction between two adjacent materials. More area of contact between human skin and fabric provides more points of contacts, which facilitate heat flow.

Bajzik [11] studied the thermal absorptivity and other properties of fabric, including structure, composition, density, humidity, chemical properties of fibers, surface treatment, temperature, and other factors. Bajzik also confirms the findings of Rengasamy, Das, and Patil [10] that thermal absorptivity has a strong link with surface roughness and contact area.

Özdil et al. used thermal absorptivity concept to find out the effect of yarn properties on thermal comfort of knitted fabrics [12]. They concluded that the loose fabrics provide high thermal resistance, high air permeability values, and warm feelings. They related warm feeling with lower thermal absorptivity values. Oğlakcioğlu et al. [13] worked on thermal comfort properties of some knitted fabrics and concluded that thermal absorptivity is highly linked with structure of a fabric.

Özçelik et al. [14] studied sensorial comfort of textile fabrics. They concluded that when fabric is tightened between fingers, it gives a feel about warm-cool feeling along with surface properties of the fabrics. Study of Özçelik et al. [14] proves that human can assess the warm-cool feeling of fabric by touching and it is one of the parameters that are given significant weightage during the selection of fabric by end users. Mangat et al. studied [15] the impact of different weft materials and washing treatments on moisture management characteristics of denim. They used thermal absorptivity to assess the warmcool feeling of denim and found a significant correlation between thermal absorptivity values measured using Alambeta. Furthermore, they also expressed that change in structure of weaving has substantial impact on thermal absorptivity. 
Thermal absorptivity is the objective measurement of warm-cool feeling of the fabric. Fabrics with a lower thermal absorptivity value have warm feeling and vice versa. It is observed that the thermal absorptivity value increases by decreasing the cotton content percentage in an inner layer of the fabric. That was due to a higher thermal conductivity of the polyester. The thermal absorptivity was calculated by using specific heat of the inside layer of the fabric that would be in contact with the body during use [16].

\section{Thermal absorptivity of solid polyester}

Thermal absorptivity of solid polyester is quite different as compared to the thermal absorptivity of a fabric made by using polyester fiber, shortly polyester, when speaking about fibers and textiles. It is caused by the presence of air and moisture in the fabric. Fiber Survey Book, published by [17] Wiley-VCH, has been used to note the thermal conductivity, density, and specific heat capacity values of polyester. The values shown in Table 1 have been used in Equation (1) to find the thermal absorptivity of polyester in solid form:

Table 1. Thermal conductivity, density, and specific heat values of polyester

\begin{tabular}{|c|c|}
\hline Description & Values \\
\hline Thermal conductivity & $0.3\left[\mathrm{~W} \mathrm{~m}^{-1} \mathrm{~K}^{-1}\right]$ \\
\hline Density & $1,450\left[\mathrm{~kg} \mathrm{~m}^{-3}\right]$ \\
\hline Specific heat & $1,600\left[\mathrm{~J} \mathrm{~kg}^{-1} \mathrm{~K}^{-1}\right]$ \\
\hline
\end{tabular}

Equation 11 is applied for the calculation of thermal absorptivity of the rib knit fabric. In this equation, thermal conductivity, density, and specific heat capacity values are substituted for solving the equation.

$$
b=\sqrt{0.3 * 1,450 * 1,600}
$$

Outcome of Equation 12 is 834 [W s s.5 $\left.\mathrm{m}^{-2} \mathrm{~K}^{-1}\right]$. This value has been used as thermal absorptivity of polyester in solid form for the calculation of thermal absorptivity of knitted rib.

\section{Thermal absorptivity equation}

In this study, a model approach has been used to calculate the thermal absorptivity of fabric. This approach is based on the factors including thermal absorptivity of polyester in solid form, porosity of a fabric, and contact points between human skin and fabric surface. As discussed in previous part of the study, certain changes took place in thermal absorptivity of the fabric because of porosity. Porosity shows the ratio of fiber to fabric; higher porosity means that the quantity of polyester was less, leaving more space for air.

Porosity is a concept that is commonly used in various fields. Militký and Havrdová [18] introduced following methods to calculate porosity.

In this study, volumetric approach proposed by Militky and Havrdova has been used to measure the porosity, as shown in Equation 13

$$
P_{H W}=1-\frac{v_{y}}{v_{V}}
$$

where $P_{H W}$ [1] represents the porosity based on volumetric density, shows the volume covered by fiber, and depicts the whole accessible volume. Following prediction equation has been developed for the prediction of contact thermal absorptivity of rib knit fabrics.

$$
A\left(1-P_{H W}\right)
$$

where $b$ represents the thermal absorptivity $\left[\mathrm{W} \mathrm{s}^{0.5} \mathrm{~m}^{-2} \mathrm{~K}^{-1}\right]$ of fabric, bp is the thermal absorptivity of polyester in solid form, $P_{H W}$ shows porosity [1], and $A$ is the contact area [1] between human skin and surface of fabric. Both porosity and contact area are unit less values. In this approach, the value of thermal absorptivity of polyester was calculated by substituting the standard values of thermal conductivity, density, and specific heat capacity values of polyester in solid form in Equation 11 and then the calculated value of thermal absorptivity of polyester in solid form is multiplied with the porosity and contact area of knitted rib to find the thermal absorptivity of rib knit fabrics. This is a novel approach that proves that using this method, thermal absorptivity of any material can be predicted. The porosity of samples used in this study is high because of its structure, and knit structure has many air gaps because of the insertion of loop and they can be well seen in the images taken from microscope (Figure 2) while measuring the contact area.

\section{Theory of theory contact absorptivity of fabrics}

Thermal absorptivity (or effusivity) is a general parameter for any solid material, and it can be used from the calculation of
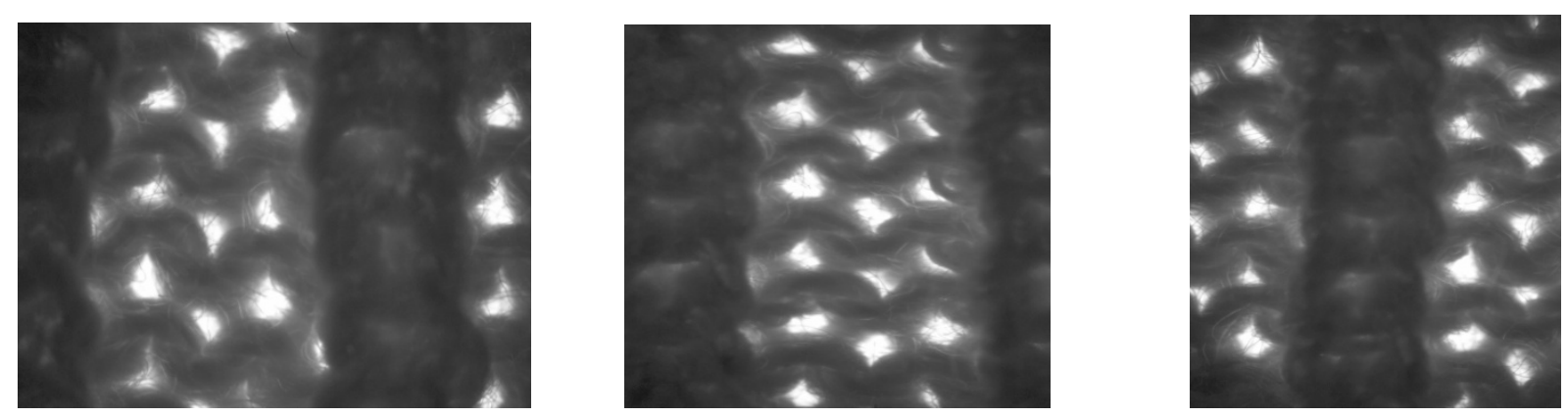

Figure 2. The white dots showing the porous media in fabric 
a steady-state contact temperature of two large (semi-infinite) bodies with different temperatures that are brought into ideal, full area mutual thermal contact. As follows from the theory, the term "thermal absorptivity" is derived from ideal boundary condition of first order on the surface of the semi-infinite body, but as will follow from the next considerations, it is not needed to be associated with the condition of ideal thermal contact with the smooth surface.

In the field of textiles, the principle of thermal absorptivity is mostly used for the determination of the contact heat flow qdyn $\left[\mathrm{W} / \mathrm{m}^{2}\right]$ between a human skin and a fabric according to the modified previously mentioned equation (bid here means the ideal smooth contact surface):

$$
\mathrm{q}_{\mathrm{dyn}}=\mathrm{b}_{\mathrm{id}}\left(\mathrm{t}_{1}-\mathrm{t}_{2}\right) /(\pi \mathrm{T})^{1 / 2}
$$

As already mentioned, in this concept, the tested (touched) fabric is considered a semi-infinite body, which can be respected if the contact time is very short. This condition corresponds to the real situation. However, in the real situations, the contact area between the human skin and the fabric is never ideal, and it can be characterized by the contact area coefficient $c_{A}$, ranging from 0 to 1 . Thus, the effective contact heat flow $q_{\text {eff }}$ will be lower according to the relationship

$$
\begin{aligned}
& q_{\text {eff }}=c_{A} \cdot q_{\text {dyn }} \\
& q_{\text {eff }}=b_{\text {id }} \cdot c_{A}\left(t_{1}-t_{2}\right) /(\pi T)^{1 / 2}
\end{aligned}
$$

Thus, the effective thermal contact absorptivity of the tested fabric can be expressed as

$$
\mathrm{b}_{\text {cont }}=\mathrm{b}_{\mathrm{id}} \cdot \mathrm{c}_{\mathrm{A}}=\mathrm{c}_{\mathrm{A}}(\lambda \rho c)^{1 / 2}
$$

Nevertheless, the validity of this simplifying relationship can be discussed: heat is also conducted in thin air gaps between the human skin and the fabric in the textured contacted surface. The possible declination of this effect may depend on much higher thermal conductivity $\lambda$ of the contacting polymer $\left(0.25-0.40 \mathrm{~W} \mathrm{~m}^{-1} \mathrm{~K}^{-1}\right)$ and then thermal conductivity of the air $\left(0.026 \mathrm{~W} \mathrm{~m}^{-1} \mathrm{~K}^{-1}\right)$. However, in thin fabrics (thickness $\mathrm{h}$ is less than $0.3 \mathrm{~mm}$ ), thermal resistance $R$ of the air gaps present in the textured surface can be quite small, as results from the following equation

$$
R=h / \lambda
$$

Therefore, the theoretical equation expressing the thermal contact absorptivity should approximate the thermal contact feeling of thicker fabrics only. Nevertheless, the mechanism of heat conduction and accumulation in the vicinity of the contact areas is complicated. Here, the short contact time is also a condition enabling the simplification of the real dynamic thermal contact transfer. As regards the formula for thermal absorptivity, it involves the conduction $\lambda$ of heat and accumulation $\mathrm{C}\left[\mathrm{J} \mathrm{m}^{\mathrm{m}-3}\right.$ $\mathrm{K}^{-1}$ ] of heat, where $\mathrm{C}=$ o.c. In a compact body, the conduction and accumulation cannot be separated in a simple way. In a body with high porosity $P$, such as textile fabrics, most of the heat will be conducted in the relatively large air gaps, whereas the accumulating mass because of the porosity will be proportionally lower, having better heat conduction in their segments. Thus, the very simplified idealized relationship for thermal capacity $\mathrm{C}$ of a porous body may get the form

$$
C_{\text {porous }}=C_{\text {full }}(1-P)
$$

Now, let us focus on the thermal absorptivity of a porous body contacting a skin. Here, there is always full polymer in a thermal contact, and in the vicinity of the contact point, there are air gaps with low thermal conductivity. Owing to short time of conduction, the more distant fabric layers are out of effect. Thus, the principle of parallel thermal resistances can be adopted here. In this principle, thermal conductivities of both components $\left(\lambda_{\text {polym }}, \lambda_{\text {air }}\right)$ can be summarized when multiplied by their weight coefficients:

$$
\lambda_{\text {porous }}=\lambda_{\text {polym }} \cdot(1-P)+\lambda_{\text {air }} P
$$

For the very porous body and compact highly conducting polymer (such as polyethersulphone), the effect of the heat conduction in the air gaps is several times lower than the heat conduction in the solid component, a fabric, and in the first approximation, this last term can be neglected. Then, when multiplying the $\lambda_{\text {porous }}$ and $\mathrm{C}_{\text {porous }}$, we get

$$
\lambda_{\text {porous }} \cdot C_{\text {porous }}=\lambda \cdot C \cdot(1-P)^{2}
$$

Thus, thermal contact absorptivity of porous fabrics touching the skin will be as follows:

$$
\mathrm{b}_{\text {porous }}=\mathrm{b}_{\text {solid }}(1-\mathrm{P})
$$

When a real porous fabric with a textured surface (ribs) touches a skin, then the idealized contacting area consists of segments made of full polymer, empty air segments $(b=0)$, and air gaps between the skin and the segmented (porous) body.

The contact area is a parameter that has been used as independent variable, whereas thermal absorptivity of polyester in solid form is constant. However, porosity has different values for all 15 samples. For calculation purpose, average value of porosity has been taken. This is done to note the impact of contact area on thermal absorptivity of rib knit fabrics only. There are two reasons to take constant value of porosity. One is that there is no significant difference in porosity of all 15 samples; the other reason is that there are many studies done earlier where the less significant factor having minor variation has been taken as constant and its values have been kept constant to have a better view of impact of most significant factor on the dependent variable [19-21].

\section{Experimental section}

\subsection{Sample description}

This study used knitted rib fabric in order to confirm the abovementioned thermal absorptivity model in dry state. A knit rib fabric is highly porous and has uneven surface profile by 

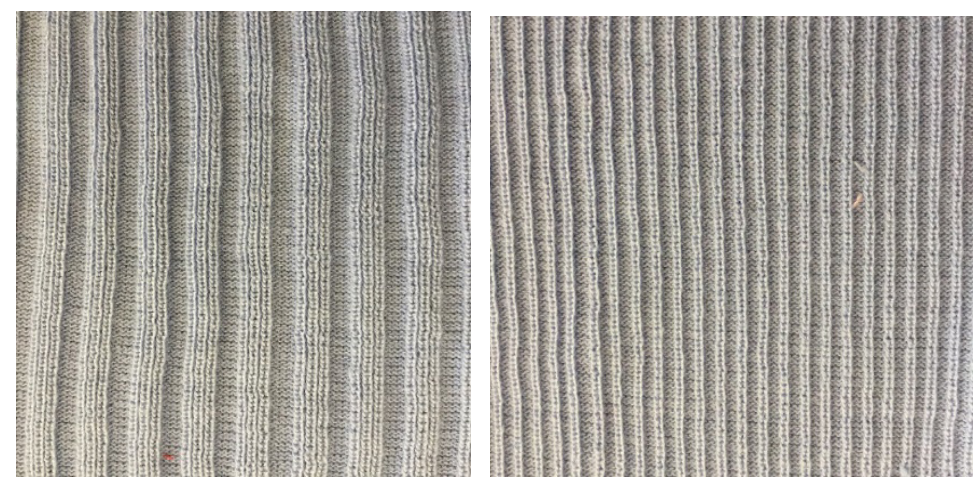

(a) $3 \times 2$ structure

(b) $1 \times 1$ structure

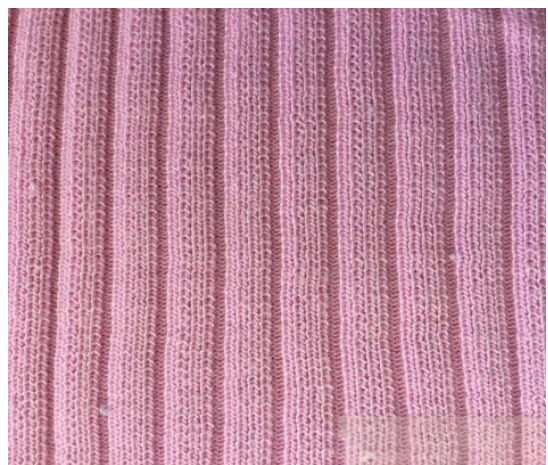

(c) $4 \times 2$ structure

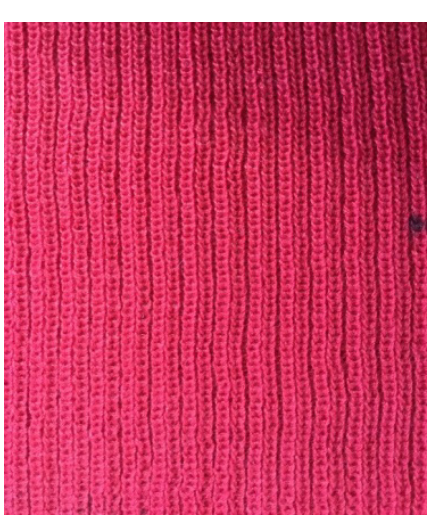

(d) $2 \times 1$ structure

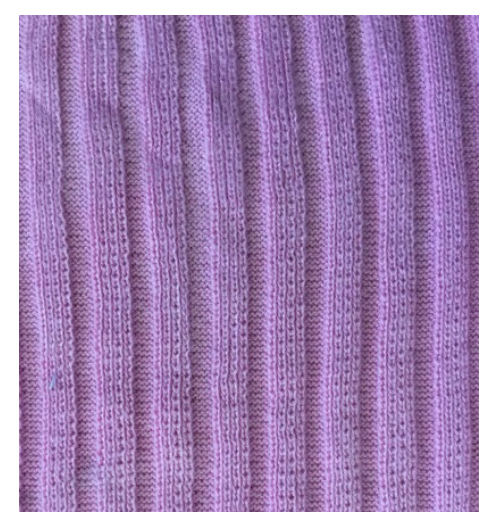

(e) $4 \times 2$ structure

Figure 3.Surface profile of rib knit fabrics

Table 2 Sample description

\begin{tabular}{|c|c|c|c|c|c|c|}
\hline Sample no. & Rib type & $\begin{array}{l}\text { Stitch length } \\
\text { per } \mathrm{cm}\end{array}$ & $\begin{array}{c}\text { Wales per } \\
\text { cm }\end{array}$ & $\begin{array}{c}\text { Courses per } \\
\text { cm }\end{array}$ & $\begin{array}{c}\text { Planner } \\
\text { weight }(g \\
\left.\mathbf{m}^{-2}\right)\end{array}$ & Contact area [1] \\
\hline 1 & $1 \times 6$ & 0.46 & 10 & 12 & 501 & 0.13 \\
\hline 2 & $1 \times 4$ & 0.47 & 11.2 & 13 & 400 & 0.23 \\
\hline 3 & $1 \times 2$ & 0.46 & 9.6 & 11.2 & 541 & 0.46 \\
\hline 4 & $2 \times 3$ & 0.49 & 9.4 & 12 & 560 & 0.51 \\
\hline 5 & $2 \times 1$ & 0.49 & 8.4 & 12 & 462 & 0.52 \\
\hline 6 & $3 \times 4$ & 0.49 & 10.4 & 10.8 & 523 & 0.54 \\
\hline 7 & $1 \times 1$ & 0.49 & 9 & 9 & 477 & 0.55 \\
\hline 8 & $2 \times 2$ & 0.44 & 9.6 & 12 & 471 & 0.59 \\
\hline 9 & $1 \times 1$ & 0.42 & 8 & 13 & 485 & 0.6 \\
\hline 10 & $3 \times 3$ & 0.42 & 8.4 & 10.4 & 548 & 0.61 \\
\hline 11 & $4 \times 4$ & 0.5 & 10.4 & 12 & 540 & 0.65 \\
\hline 12 & $2 \times 1$ & 0.49 & 8.2 & 10 & 540 & 0.71 \\
\hline 13 & $4 \times 3$ & 0.51 & 7 & 9 & 378 & 0.76 \\
\hline 14 & $4 \times 2$ & 0.51 & 10 & 12 & 422 & 0.79 \\
\hline 15 & $3 \times 1$ & 0.47 & 8.2 & 10 & 447 & 0.81 \\
\hline
\end{tabular}


nature. Surface profile of rib knit fabric is quite distinguishableas compared to normal knitted fabrics (Figure 3). Surface of knitted rib fabric is made quite uneven using different knitting techniques, normally denoted by $1 \times 1,1 \times 2,2 \times 1$, and so on. For this study, 15 samples of rib knit fabrics using $100 \%$ polyester yarn were produced on a flat knitting machine of 12 gauge (12 needles per inch) having 50 count same for all the samples. There was no significant difference between thicknesses of the samples. The thickness ranges from 1.38$1.40 \mathrm{~mm}$. Main differences existed in the surface profile and planar weight $\left[\mathrm{g} \mathrm{m}^{-2}\right]$.

Surface of rib knit fabrics is divided into two main categories: fins and base. There are fins on the surface of knitted rib. These fins are called vertical stripes (columns) and also as wale. Rest of the area is called base of the knitted rib fabric. Vertical columns are separated by reverse stitches. After changing the surface profile using different knitting techniques, a significant change in contact area is expected when a touch is made between hands and rib knit fabric, which leads to the change in thermal absorptivity as it is discussed in previous pages that thermal absorptivity has a strong dependency on contact area.

\section{Method of research}

The measurement of thermal absorptivity of the fabric in a dry state requires the use of an exceptional testing instrument that allows the researchers to note a measurement quickly in a few seconds after creating a touch or interaction between the two surfaces having temperature difference of $10^{\circ} \mathrm{C}$. One of the exceptional instruments using which thermal absorptivity can be measured within a few seconds is Alambeta (Sensora,

\section{Czech Republic).}

The Alambeta is computer-controlled, semiautomatic, nondestructive equipment that is very helpful for measuring the thermal conductivity, thermal resistance, thermal absorptivity, heat flux, and thickness. Before testing, all samples were kept in laboratory under controlled environment, where temperature was maintained at $20 \pm 2^{\circ} \mathrm{C}$.

\section{Results and Discussion}

Theoretical models that were developed (Equation 4) have been used for the prediction of thermal absorptivity of knitted rib. In this equation, contact area between plat and knitted rib has been used. For measuring contact area, images of the samples have been used. The images were taken using electronic microscopes and then analyzed. From Figure 1, it is clear that knitted rib has two types of surface. Elevated portion touches the hand when hand is put on the fabric surface. Using these images, elevated area and nonelevated area have been measured, which gave the percentage of contact area of rib when it is touched with any human hand or any plate.

Measured and predicted values of thermal absorptivity of rib fabric are given in Table 3. Moreover, in Table 3, values of thermal absorptivity of polyester in solid form, average porosity, and contact area have been given. All these values have been used in Equation 4 to find out the thermal absorptivity of rib knit fabrics. It shows that the suggested model can be used for the prediction of thermal absorptivity of rib fabric. It can be said that this model can work for any fabric having distinguished surface

Table 3. Comparison of measured and predicted values of thermal absorptivity

\begin{tabular}{|c|c|c|c|c|}
\hline $\begin{array}{c}\text { Sample } \\
\text { no. }\end{array}$ & $\begin{array}{c}\text { Contact area assumed } \\
(\mathbf{\%})\end{array}$ & $\begin{array}{c}\text { Contact area measured } \\
(\mathbf{\%})\end{array}$ & $\begin{array}{c}\text { Thermal absorptivity of } \\
\text { rib calculated }\end{array}$ & $\begin{array}{c}\text { Thermal absorptivity of } \\
\text { rib measured }\end{array}$ \\
\hline 1 & 0.15 & 0.13 & 34 & 77 \\
\hline 2 & 0.2 & 0.23 & 45 & 102 \\
\hline 3 & 0.25 & 0.46 & 56 & 114 \\
\hline 4 & 0.3 & 0.51 & 68 & 107 \\
\hline 5 & 0.35 & 0.52 & 79 & 115 \\
\hline 6 & 0.4 & 0.54 & 101 & 120 \\
\hline 7 & 0.45 & 0.55 & 113 & 129 \\
\hline 8 & 0.5 & 0.59 & 124 & 135 \\
\hline 9 & 0.55 & 0.6 & 135 & 139 \\
\hline 10 & 0.6 & 0.61 & 146 & 145 \\
\hline 11 & 0.65 & 0.65 & 158 & 163 \\
\hline 12 & 0.7 & 0.71 & 169 & 171.3 \\
\hline 13 & 0.75 & 0.76 & 180 & 181.5 \\
\hline 14 & 0.8 & 0.79 & 191 & 195.6 \\
\hline 15 & 0.85 & 0.81 & & \\
\hline
\end{tabular}


profile for the prediction of thermal absorptivity.

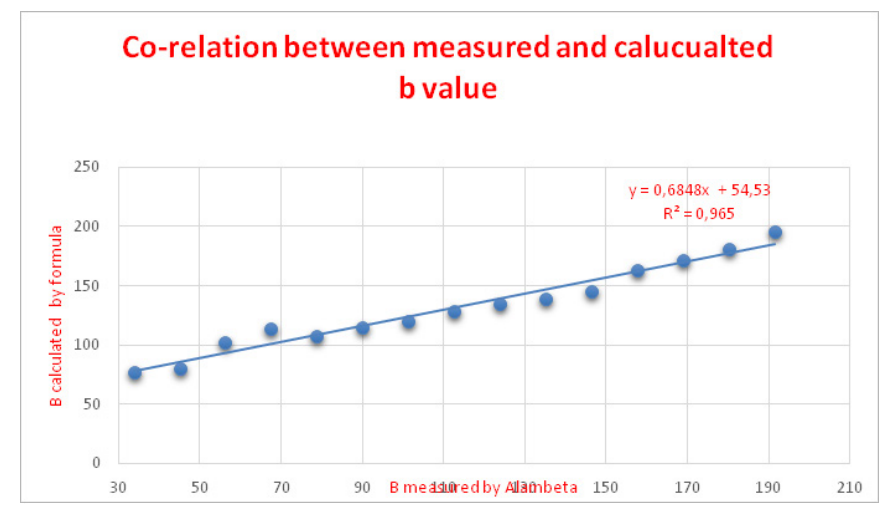

Figure 4. Correlation between measured and calculated values

In Figure 4, there is a correlation between calculated and measured values of thermal absorptivity; this shows that both values are 0.96 , which is being explained by independent value. Graphical representation (Figure 5) shows that there is a substantial agreement between measured and calculated values. It shows that the suggested model can be used for the prediction of thermal absorptivity of rib fabric. It can be said that this model can work for any fabric having distinguished surface profile for the prediction of thermal absorptivity. This model can be used for any type of rib where the contact area is known and the fabric thermal properties are measured.

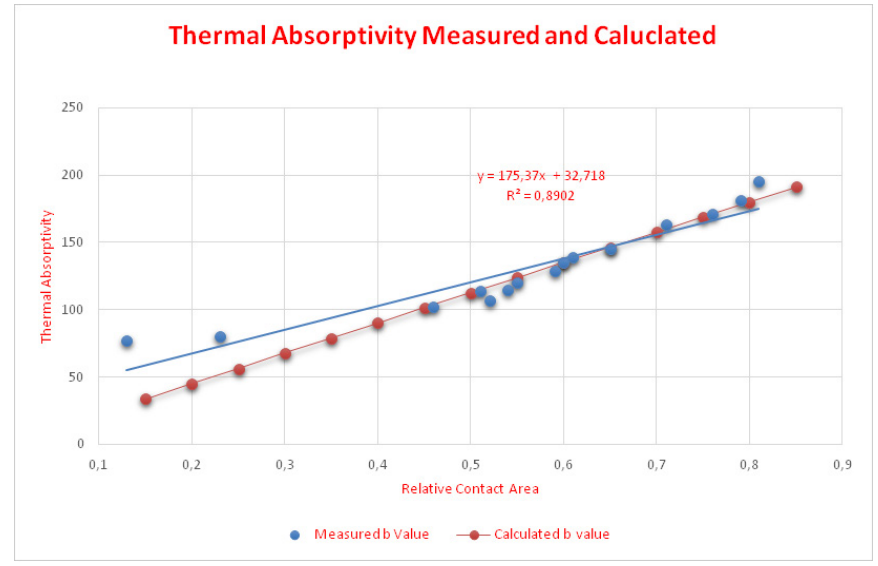

Figure 5. Graphical representation of measured and calculated values of thermal absorptivity.

\section{Conclusions}

This study aims to investigate the variations in thermal conductivity, thermal absorptivity, and thermal resistance because of the alteration in surface profile of knitted rib fabric and develop a model for the extrapolation of thermal absorptivity because of variation in interaction area between human skin and knitted rib fabric. Warm-cool feeling is one of the parameters that play a vital role in thermophysiological comfort. It is also known as thermal absorptivity. Thermal absorptivity is measured with the help of an instrument. Thermal absorptivity has a strong correlation with fabric structure and type of fibers. Surface profile determines the contact area between human skin and fabric. Many studies have proved that contact area between fabric and human skin controls the warm-cool feeling during initial touch. Keeping its importance in view, a physical model has been developed for the prediction of thermal absorptivity of any fabric. The suggested model has been used to predict the thermal absorptivity values of 15 different knitted ribs produced using $100 \%$ polyester. For the development of knitted rib fabric, double-knit rib knitting machine has been used. Samples were kept under standard conditions and tested using Alambeta. Thermal absorptivity was measured and compared with predictive values of knitted rib using models. It was observed that significant correlations exists between thermal absorptivity observed and calculated, which shows that suggested models can be used for the prediction of thermal absorptivity of any material having distinct surface. The above model has significant correlation between measured and calculated values, which shows that by using this equation, one can easily find the thermal absorptivity of any fabric which has thickness, thermal conductivity, and porosity measured. this model can be used to predict the thermal comfort level of human body up to certain contact interaction with human body. Contact point increases the thermal conductivity and thermal absorptivity in human body while interacting with clothes, which is feasible in hot weather; as the thermal absorptivity level is increasing, body feels more cool, which is important in hot weather but not likely appreciated in hot weather.

\section{References}

[1] Pac, M.J., Bueno, M., and Renner, M., Warm-Cool Feeling Relative to Tribological Properties of Fabrics. Textile Res. J., , 2001. 71(9): p. 806-812.

[2] Tzanov, T., Betcheva, R., and Hardalov, I. , Thermophysiological comfort silicone softeners-treated woven textile materials. International Journal of Clothing Science and Technology, 1999. 11(4): p. 189-197.

[3] Mitra, A., Majumdar, A. Majumdar, P. K., Bannerjee, D., Predicting Thermal Resistance of Cotton Fabrics by Artificial Neural Network Model. Experimental Thermal and Fluid Science 2013. 50: p. 172-177.

[4] Hes, L., Thermal properties of nonwovens. Congress Index 87Genf, 1987.

[5] Hes, L., Non-destruction determination of comfort parameters during marketing of functional garment and Apparels. Indian Journal of Fiber and Text. Research, 2008(33): p. 239-245.

[6] Hes, L., and Dolezal, I, New Method and Equipment for Measuring Thermal Properties of Textiles J. Textile Mach. Soc. Jpn, 1989(71): p. 806-812,.

[7] Hes, L., and Stanek, J., Theoretical and Experimental Analysis of Heat Conductivity for Nonwoven Fabrics. in NDA-TEC Transactions, Philadelphia, 1989.

[8] Hes, L., Dolezal, I. , New Method and Equipment for Measuring Thermal Properties of Textiles. Sen i Kikai Gakkaishi (Journal of the Textile Machinery Society of Japan), 1989. 42(8): p. 124-128.

[9] Hes, L., Araujo, M. D., and Djulay, V. V. , Effect of Mutual Bonding of Textile Layers on Thermal Insulation and Thermal Contact Properties of Fabric Assemblies. Textile 
Research Journal, 1996. 66( 4): p. 245-250.

[10] Rengasamy, R.S., Das B.R., Patil, Y.B. , Thermophysiological comfort characteristics of polyester air-jettextured and cotton-yarn fabrics The Journal of The Textile Institute., 2009. 100(6): p. 507-511.

[11] Bajzík, V., Hand prediction using ordinal logistic regression, in Innovations in Clothes and Footwear conference. 2010: Kazimierz Pulaski Technical University of Radom. p. 191198.

[12] Özdil, N., Marmaralı, A., and Kretzschmar, S.D., Effect of yarn properties on thermal comfort of knitted fabrics. International Journal of Thermal Science, 2007. 46(12): $p$. 1318-1322.

[13] Oğlakcioğlu, N., \& Marmarali, A. , Thermal Comfort Properties of Some Knitted Structures. FIBRES \& TEXTILES in Eastern Europe 2007. 15(5-6): p. 64-65.

[14] Özçelik, G., et al Sensorial Comfort of Textile Materials, in Woven Fabrics, H.-Y. Jeon, Editor. 2012, InTech, .

[15] Mangat, M.M., Hussain, T., Bajzik, V. , Impact of Different Weft Materials and Washing Treatments on Moisture
Management Characteristics of Denim. Journal of Engineered Fibers and Fabrics 2012. 7(1): p. 38-49.

[16] Afzal, A., et al., Influence of fabric parameters on thermal comfort performance of double layer knitted interlock fabrics. Autex Research Journal, 2013.

[17] Wiley-VCH, ed. Ullmann's Fibers,. Vol. 1. 2008, Verlag $\mathrm{GmbH} \&$ Co. KGaA, Weinheim.

[18] Militký, J., and Havrdová, M., Porosity and air permeability of composite clean room textiles. International Journal of Clothing Science and Technology, 2001. 13(3/4): p. 280289.

[19] Mangat, M.M., Hes, L. Bajzik, V., Thermal resistance models of selected fabrics in wet state and their experimental verification. Textile Research Journal, 2014. 85: $p$. 200-210.

[20] Mangat, M.M., The Effect of Moisture and Finishing on Thermal Comfort And Selected Mechanical Properties of Denims With a Portion of Synthetic Fibres in Textile Engineering. 2012, Technical University Liberec: Liberec Czech Republic.

[21] Militky, J., et al., Characterization of yarn irregularity and variation in yarn diameter, in Beltwide Cotton Conferences. 2010: New Orleans, Louisiana. 